\title{
SANEAMENTO COMO FERRAMENTA PARA A SUSTENTABILIDADE DA ÁREA QUILOMBOLA VILA ESPERANÇA, LAPA, PR
}

SANITATION AS A TOOL FOR THE SUSTAINABILITY OF QUILOMBOLA VILA ESPERANÇA AREA, LAPA, PR, BRAZIL

\section{Mirian Desplanches Mercado (1)}

Engenheira civil. Mestre em Gestão Ambiental pela Universidade Positivo. Professora do curso de Engenharia Civil da Universidade Positivo - Curitiba (PR), Brasil.

\section{Selma Aparecida Cubas(0)}

Doutora em Hidráulica e Saneamento pela Escola de Engenharia de São Carlos da Universidade de São Paulo (USP). Professora adjunta do Departamento de Hidráulica e Saneamento do Programa de Pós-Graduação em Engenharia de Recursos Hídricos e Ambiental da Universidade Federal do Paraná (UFPR) - Curitiba (PR), Brasil.

\section{Mario Sergio Michaliszyn (D)}

Doutor em Ciências Sociais Antropologia pela Pontifícia Universidade Católica de São Paulo (PUC-SP). Professor do Programa de Pós-Graduação em Gestão Ambiental da Universidade Positivo - Curitiba (PR), Brasil.

\section{Endereço para correspondência:}

Mirian Desplanches

Mercado - Rua Francisco

Rocha, 1.640, ap. 2.304-

Bigorrilho - CEP 80730-390 -

Curitiba (PR), Brasil - E-mail:

miriandesplanches@hotmail.com

Recebido em: 15/09/2017

Aceito em: 12/06/2018

\section{RESUMO}

Entre os principais problemas enfrentados por comunidades localizadas em áreas rurais ou periurbanas, destaca-se a precariedade de ações no âmbito do saneamento. Cenário, esse, que favorece a veiculação de doenças e outros agravos de ordem social que contribuem para a manutenção das condições de vulnerabilidade social, além dos impactos negativos causados aos sistemas ecológicos. Tal situação é identificada na Comunidade Remanescente Quilombola Vila Esperança de Mariental no município da Lapa, estado do Paraná. O presente trabalho apresenta um plano de ações voltadas ao saneamento como princípio de sustentabilidade, construído a partir de um diagnóstico sobre a situação ambiental e socioeconômica da população e que, aliado ao projeto de educação ambiental proposto, pode servir como fio condutor de mudanças naquela realidade no que diz respeito a melhorias das condições sociais e de saúde da população, além de contribuir para a sustentabilidade local. Dentre as alternativas, foram propostos sistemas de tratamento de esgoto com zonas de raízes.

Palavras-chave: sistemas descentralizados; zona de raízes; educação ambiental.

\section{ABSTRACT}

Lack of actions in the sphere of sanitation stands out among the main problems faced by communities located in rural or peri-urban areas. This context contributes to the propagation of diseases and to other social grievances, leaving them in a condition of social vulnerability, in addition to the negative impacts caused to the ecological systems. The "Vila Esperança de Mariental Quilombola Remnant Community" - LAPA, PR exemplifies this situation. This study proposes an action plan that aims the sanitation as a sustainability principle for this community. This plan was elaborated from a primary diagnosis of this population's environmental and socioeconomic situation, that along with the proposed environmental educational project, may serve as a guiding tool for a change in these people's reality. In this way, such actions can configure a strategy to improve the population's health as well as their social conditions, besides the contribution to the local sustainability. Among the alternatives, sewage treatment systems with constructed wetlands were proposed.

Keywords: decentralized systems; root zones; environmental education. 


\section{INTRODUÇÃO}

A falta ou inadequação de sistemas de saneamento ambiental em comunidades que residem em áreas rurais ou periurbanas causam prejuízos aos sistemas ambientais que as rodeiam, acarretando em piora na qualidade da saúde de seus moradores.

Neste cenário, encontram-se grupos com estilos de vida e vínculos a ambientes naturais específicos, como é o caso das Comunidades Tradicionais Remanescentes Quilombolas (CRQs). Estima-se que existam cerca de 3.500 grupos desse tipo em 300 cidades brasileiras (UNICEF, 2014). Até o primeiro semestre de 2016, a Fundação Cultural Palmares (FCP), entidade vinculada ao Ministério da Cultura (MinC), havia certificado 2.849 comunidades, entre as quais 37 localizadas no estado do Paraná.

Tais grupos se organizam a partir de valores socioculturais trazidos por africanos ao Brasil no período escravista. Para essas pessoas, construir um quilombo era um imperativo de sobrevivência, tendo em vista que foram abandonados à própria sorte, desprovidos de patrimônio, vivendo na mais absoluta miséria e constituindo territórios próprios caracterizados pela vivência comunitária (BRASIL, 2004; 2013).

Historicamente, o modelo de desenvolvimento universalista e homogêneo ignorou a diversidade humana destas comunidades, submetendo-os à invisibilidade e ao isolamento. Assim, foram expostas a todo tipo de conflito para manter suas terras, ao empobrecimento, à degradação ambiental, à expulsão de seus territórios e à intolerância religiosa, além do baixo investimento para o desenvolvimento em bases sustentáveis e aumento das suas atividades produtivas (BRASIL, 2016).

Embora o direito à proteção das manifestações populares e de seus valores culturais sejam reconhecidos pela Constituição Federal Brasileira nos artigos 215 e 216, existem algumas especificidades no que se refere ao movimento quilombola. Suas reivindicações referem-se ao reconhecimento étnico, simbolizado no respeito à memória, tradição e valores culturais, bem como o reconhecimento de direitos sociais. Elas são formuladas com base nos discursos que vinculam a defesa da igualdade e do respeito à alteridade. Sendo assim, a delimitação das pautas políticas dos discursos é parte da construção da sua identidade (BRASIL, 1988; SANTOS, 2014).
Apesar disso, permanecem fortes os traços identitários nas CRQs, produzidos pelo senso comum e pelo imaginário social, que associam o quilombo a um contexto histórico específico, de fuga da escravidão e de formação de comunidades precárias, reunidas por frágeis laços institucionais em locais de difícil acesso. Também continuam as pendências fundiárias que dificultam a aquisição de uma identidade definitiva (VALENTIM; TRINDADE, 2011).

Atualmente, a desigualdade social das CRQs, materializada pela ausência de direitos essenciais, ainda é uma realidade. Barros (2007) afirma que as condições de vida destas populações são marcadas pela segregação racial e aos resultados dela, como o desemprego, a baixa escolaridade, as condições de habitação precárias e a falta de acesso a serviços de saúde e de transporte. Estando, assim, expostas a extrema vulnerabilidade social e simbólica, onde o critério de auto definição representa a esperança do reconhecimento político e da detenção de direitos (SAHR et al., 2011).

Em relação à territorialidade, nestas comunidades prevalece o uso comum, respeitando laços de parentesco e vizinhança, assentados em relações de solidariedade e reciprocidade (NERY, 2004), com predomínio de práticas comuns de cultivo. Consequentemente, suas atividades estão baseadas na utilização de recursos naturais renováveis existentes no ecossistema em que estão inseridos (SILVESTRE; MOREIRA, 2012).

Entretanto, nessas comunidades os serviços de saneamento prestados são inexistentes ou precários. Normalmente, o abastecimento de água é individual, por meio de poços, fontes de água, cisternas ou outras fontes, sem tratamento. Apenas as comunidades localizadas em áreas periféricas aos centros urbanos recebem água tratada. A coleta e tratamento de esgoto são praticamente inexistentes. O destino dos esgotos sanitários são valas a céu aberto, fossas rudimentares ou o lançamento direto em corpos hídricos. Quanto aos resíduos sólidos, poucas comunidades têm coleta realizada pelo município. Na maioria dos casos, os resíduos são jogados a céu aberto em terrenos baldios, enterrados no fundo das residências ou queimados (GTCM, 2010; BRASIL, 2013).

A exemplo destas comunidades, apresenta-se a Comunidade Remanescente Quilombola (CRQ) Vila Esperan- 
ça de Mariental, localizada no município da Lapa (PR), que não possui planejamento urbanístico e as condições de algumas moradias são precárias. Embora disponham de abastecimento de água potável, não se tem acesso a sistema de coleta e tratamento de esgotos sanitários, bem como qualquer outra ação no contexto do saneamento ambiental, resultando na contaminação do meio ambiente e na veiculação de doenças.

Cenário que, segundo Scriptore (2016), pode impactar o perfil de morbidade de uma região a longo prazo, ter graves consequências para a aquisição de anos de escolaridade e, dessa forma, gerar comprometimento de ganhos salariais e de produtividade no futuro. Além disso, esses efeitos deletérios, da falta de infraestruturas essenciais, propagam as sementes do subdesenvolvimento social e educacional, gerando um ciclo de pobreza e agravos de ordem física e emocional.

Portanto, o suprimento das carências de abastecimento de água e a expansão de ações para que a população deixe de conviver com esgotos sanitários a céu aberto e tenha acesso a serviços de tratamento e disposição final adequada de resíduos sólidos é fundamental para a melhoria da qualidade de vida e de saúde das populações, tornando-se uma questão social e de saúde pública urgentes (BRASIL, 2004).

Por outro lado, o planejamento de políticas de gestão ambiental, nos propósitos do manejo integrado dos recursos naturais, tecnológicos e culturais de uma sociedade, leva à necessidade de compreender as interações das demandas históricas, econômicas, ecológicas, políticas e culturais e da direção do desenvolvimento. Nessa perspectiva, a ciência e a tecnologia para o desenvolvimento sustentável agregam o saber tecnológico e antropológico ao saber técnico (BEZERRA; BURSZTYN, 2000).

Leroy e Acselrad (2000) complementam que os objetivos da sustentabilidade ambiental, da equidade entre gêneros, da erradicação da pobreza, do respeito aos direitos humanos, do pleno emprego e da integração social compõem um processo complexo que envolve conflito e cooperação, desde a escala local até o âmbito global, bem como uma variedade de atores como governos, organismos internacionais, entidades empresariais e organizações cidadãs.

Para Silva (2015), a sustentabilidade no saneamento consiste em buscar os objetivos primordiais: as viabi- lidades econômica, social e ambiental, a promoção do bem-estar, a realização de serviços ambientais e a meIhoria da saúde pública. Barbosa (2008) complementa que a sustentabilidade consiste em encontrar meios de produção, distribuição e consumo dos recursos de forma mais coesa, economicamente eficaz e ecologicamente viável. Nessa interação, é importante identificar soluções de engenharia que se adequem à realidade local, apresentem baixo custo e sejam eficientes nos propósitos a que se destinam. Importante considerar, ainda, que possam contribuir para reduzir a exclusão social e econômica das populações menos favorecidas, melhorando a qualidade de vida e a proteção dos recursos naturais.

Além disso, a descentralização dos serviços de saneamento representa um instrumento para a sustentabilidade e o desenvolvimento de uma comunidade, já que essas adequações representam a melhoria da qualidade de vida com ganhos em saúde, na capacidade local para atendimento dos serviços e efetivo controle social. E permite, ainda, que a comunidade reflita sobre suas práticas e atitudes em relação ao meio ambiente, assim como evidencia a sua capacidade de autonomia e de cidadania (PHILIPPI JR, 2005).

Mendonça e Mendonça (2016) reiteram que para atender a esta demanda é ideal a adoção de soluções simples, como os sistemas de tratamento de esgoto que não utilizam energia elétrica na sua operação e permitem investimentos e custos operacionais inferiores aos demais. Destaque para as fossas sépticas, também denominadas decanto-digestores, onde o esgoto sofre a ação de bactérias anaeróbias capazes de realizar a digestão da matéria orgânica e eliminar de forma parcial os organismos patogênicos. Os efluentes deste sistema podem ser lançados em sumidouros, valas de filtração ou, ainda, passar por sistemas complementares antes da disposição final (VON SPERLING, 2014; CREDER, 2015).

Ainda como opção acessível, de simples implantação e operação, estão os sistemas de zona de raízes, constituídos de uma área escavada pouco profunda preenchida com um material filtrante, geralmente areia ou cascalho, e plantas com vegetação tolerante a condições saturadas (UN-HABITAT, 2008). Zurita, Anda e Belmont (2009) acrescentam que esses sistemas podem ser muito úteis em países em desenvolvimento, tendo em vista que apresentam tecnologia simples e envolvem baixos custos operacionais e de implantação, podendo 
ser construídos com materiais locais. Além disso, apresentam-se como uma tecnologia eficiente na remoção de patógenos, nutrientes, metais tóxicos e poluentes orgânicos. À medida que a água flui lentamente através da zona úmida, as partículas se assentam, os agentes patogênicos são destruídos e organismos e plantas utilizam os nutrientes (USEPA, 2000; HOFFMANN et al., 2011). Em tais sistemas, o crescimento microbiano, aderido ao substrato e às raízes da vegetação e em suspensão, é responsável pela remoção de compostos orgânicos solúveis, que são degradados biologicamente por micro-organismos aeróbios e anaeróbios (PHILIPPI; SEZERINO, 2004).

No Brasil, as primeiras experiências com a utilização dos sistemas de zona de raízes na melhoria da qualidade das águas e no controle da poluição foram conduzidas em 1980 pelos pesquisadores Salati e Rodrigues. Já em 1999, Philippi, Costa e Sezerino apresentaram o desempenho de tratamento de um sistema de zona de raízes (com área superficial de $450 \mathrm{~m}^{2}$ ) pós-tanque séptico, implantado em 1994. Este sistema se manteve em operação contínua e apresentou melhora significativa de desempenho ao longo de mais de 10 anos de operação. Quanto à remoção de demanda química de oxigênio (DQO) e demanda bioquímica de oxigênio (DBO), passou de $71 \%$ e $69 \%$, respectivamente, para aproximadamente $98 \%$ de remoção para ambos os parâmetros (SEZERINO et al., 2015).

A escolha das plantas a serem empregadas nos sistemas está, basicamente, relacionada à tolerância das mesmas em ambientes encharcados, ao seu potencial de crescimento, à presença da espécie nas áreas onde o sistema será implantado (principalmente devido a adaptações climáticas, custo do plantio e manutenção) e, ainda, às possibilidades de reaproveitamento (IWA, 2000). Segundo Tilley et al. (2014) qualquer vegetação nativa, com raízes profundas e largas, que possa crescer em ambientes úmidos e ricos em nutrientes, pode ser considerada.

Rodrigues (2012) relata a eficiência de um sistema de tratamento descentralizado de esgotos, composto de fossa séptica, filtro anaeróbio e sistema de zona de raízes implantado em uma escola rural no município de Campos Belos, SC. O sistema apresentou uma eficiência média de 72,1 e $77,4 \%$ na remoção de matéria orgânica, medida em termos de DBO e DQO, respectivamente. A remoção de nutrientes ficou acima de $80 \%$ e a remoção de patógenos acima de $90 \%$.
Outro sistema com configuração semelhante foi implantado por Kaick (2002) para o tratamento de efluentes sanitários de residências localizadas na Ilha Rasa, litoral do Paraná. O sistema implantado foi avaliado por um período de seis meses e teve como eficiência média de remoção: $\mathrm{DBO}_{5} 83,9 \%$, DQO $81,6 \%$ e o valores médios de $\mathrm{pH}$ no efluente ficaram em torno de 7,8 .

Ávila et al. (2015) avaliaram a eficiência de um sistema híbrido de zona de raízes construído em larga escala para o tratamento e reutilização de águas residuais domésticas em pequenas comunidades. O sistema consistia em um fluxo vertical de sub-superfície (VF) de $317 \mathrm{~m}^{2}$, um fluxo horizontal de subsuperfície (HF) de $229 \mathrm{~m}^{2}$ e outro de superfície de água livre de $240 \mathrm{~m}^{2}$ (FWS) operando em série. Os sistemas de VF e HF foram plantadas com Phragmites australis e o de FWS continha uma mistura de espécies de plantas. A eficiência média de remoção de DBO foi de $98-99 \%$. A retirada dos contaminantes emergentes estudados, que incluíam vários produtos farmacêuticos, produtos para cuidados pessoais e desreguladores endócrinos, também se apresentou eficiente, ficando acima de $80 \%$ para todos os compostos. As taxas foram alcançadas devido às altas temperaturas, bem como as diferentes condições físico-químicas existentes em diferentes configurações de sistemas, o que permitiria combinação e sinergia de vários mecanismos de remoção.

Sabei (2015) relata a experiência na implantação de cinco unidades de tratamento de esgoto composto de fossas sépticas e sistemas de zona de raízes para o tratamento de esgotos domésticos em uma comunidade rural do município de São José dos Pinhais, PR. Os dois primeiros foram projetados para atender espaços de eventos, com público estimado de até 160 e 450 usuários, respectivamente. O terceiro e quarto sistemas foram projetados para atender uma única residência unifamiliar cada, com 3 e 4 usuários, respectivamente. E o último para atender um restaurante com demanda de até 150 refeições diárias. As vegetações utilizadas nos sistemas de zona de raízes foram Zantedeschia aethiopica (copo-de-leite), Cyperus papyros (papirus) e Canna indica (cana-da-índia). A média de remoção de poluentes, após aproximadamente 12 meses de implantação, foi de, aproximadamente, em termos de DBO $56 \%$; DQO 83\%; fósforo total $75 \%$; coliformes totais 85\%; e Escherichia coli $86 \%$. O custo médio de implantação dos sistemas foi de aproximadamente $\mathrm{R} \$ 21$ por pessoa. 
Outros dois sistemas implantados na cidade de Florianópolis, SC, foram monitorados ao longo de 24 meses de operação por Trein et al. (2015). O primeiro foi projetado para atender um equivalente populacional de 250 pessoas e o segundo para receber esgoto de 2.200 pessoas, mas no período de monitoramento recebia de apenas 100. A remoção média de poluentes foi de, aproximadamente, em termos de $\mathrm{DBO}_{5} 92 \%$; DQO 84\%; e fósforo total $78 \%$.

Hijosa-Valsero et al. (2016) avaliaram sete sistemas de zona de raízes com diferentes configurações de projeto, lidando com águas residuárias urbanas tratadas primariamente quanto à concentração, distribuição e destino de dez produtos farmacêuticos e de cuidados pessoais. Além do afluente e do efluente, foram analisados o substrato, as raízes de plantas e a água dos poros. Como resultado, os autores apontaram para uma boa eficiência de remoção dos compostos nos sistemas avaliados, ampliando as vantagens do uso deste tipo de sistema.

Prata et al. (2013) realizaram um estudo para avaliar a eficiência de quatro sistemas de zonas de raízes cultivadas com vegetação ornamental Hemerocallis flava (lírio-amarelo). Tiveram como meio suporte a brita 0 , pedras com dimensões variando entre 4,5 e 9,5 mm, e foram submetidos às taxas de carregamento orgânico de esgoto sanitário, em termos de DBO de 44, 98, 230 e $395 \mathrm{~kg} \mathrm{ha}^{-1} \mathrm{~d}^{-1}$ e tempo de detenção hidráulica de 3,9; 2,0; 1,0 e 0,75 dias, respectivamente. Os sistemas foram avaliados durante seis meses de operação e todos apresentaram elevada eficiência na remoção de Sólidos Suspensos Totais (SST), DBO e DQO, atendendo aos padrões de lançamento de efluentes estabelecidos na legislação ambiental do estado de Minas Gerais.

Zurita, Anda e Belmonte (2009) investigaram a aplicação de quatro espécies de plantas ornamentais de valor comercial em sistemas de zonas de raízes, em escala piloto. Os sistemas de escoamento subsuperficial estudados apresentavam regime de fluxo horizontal e vertical. As espécies utilizadas foram Zantedeschia aethiopica, Strelitzia reginae, Andreanum do antúrio e Agapanthus africanus. Além do monitoramento semanal de parâmetros químicos e biológicos do efluente na entrada e saída dos sistemas, também foram analisadas a temperatura ambiente, a umidade e o crescimento das plantas. Foi verificado que as taxas de remoção de poluentes nos sistemas dependem do tipo de fluxo a ser adotado, sendo relatada maior eficiência nos sis- temas de fluxo vertical devido a uma melhor oxigenação. $O$ tipo de vegetação também influenciou a taxa de remoção de alguns poluentes, como a Demanda Bioquímica de Oxigênio (DBO), Demanda Química de Oxigênio (DQO), Sólidos Suspensos Totais (SST) e Fósforo Total (TP). Para estes poluentes, os sistemas plantados com três espécies diferentes foram mais eficazes, indicando que a distribuição das raízes forma um habitat microbiano diversificado em comparação aos sistemas de monocultura. Em relação ao comportamento das plantas, todas sobreviveram aos 12 meses de estudo. A espécie Z. aethiopica teve melhor desenvolvimento no sistema de fluxo horizontal, enquanto as espécies $S$. reginae e $A$. africanus se desenvolveram melhor no de fluxo vertical. Tais resultados sugerem que é possível produzir flores comerciais em sistemas de zonas de raízes sem reduzir a eficiência do tratamento (ZURITA; ANDA; BELMONTE, 2009).

A produção de flores ornamentais em sistemas de tratamento de esgoto representa mais um benefício agregado aos sistemas de zona de raízes pois, além da harmonia paisagística e dos benefícios ambientais e de saúde pública, podem representar uma fonte de renda para as famílias atendidas, com sua comercialização. Além disso, Nogueira et al. (2006) ressaltam que os custos de implantação dos sistemas se reduzem com o aumento da população atendida, não causam ruídos e agregam valor paisagístico na região de implantação, fator que contribui para a aceitação da população, quando comparados aos sistemas convencionais de tratamento.

Para Zurita, Anda e Belmonte (2009), apesar de todos os benefícios apontados em diversos estudos, o emprego de sistemas de zona de raízes é menor nos países em desenvolvimento, quando comparados à sua utilização em países da Europa e nos Estados Unidos, apesar do enorme potencial e da grande necessidade de esses países implantarem sistemas de tratamento de baixo custo. O clima favorável e a riqueza da biodiversidade também são pontos positivos, pois permitem a utilização de espécies não convencionais de plantas, como as ornamentais de interesse comercial.

Entretanto, para que as soluções alcancem seus objetivos, é fundamental que sejam desenvolvidas ações educativas que visem facilitar a compreensão sistêmica que a situação exige, estimulando a participação popular no desenvolvimento e implementação das mesmas (BRASIL, 2009). 
Nesta perspectiva, a educação ambiental torna-se grande aliada no âmbito das mudanças de comportamento da sociedade em favor do convívio harmônico com a natureza. Assim como a construção de uma relação mais harmoniosa e economicamente mais eficaz junto às populações locais valorizando a sua cultura, conhecimentos e práticas de uso dos recursos, e seus direitos enquanto cidadãos, podem apontar caminhos mais adequados para um desenvolvimento mais sustentado do meio ambiente (ARRUDA, 1999).

Dessa forma, a educação ambiental (EA) configura-se como um importante componente estratégico em busca de um novo paradigma por meio do qual os indivíduos entendam como funciona o ambiente, o quanto se depende dele, como se afeta e se promove a sua sustentabilidade. Consequentemente, a EA busca desenvolver conhecimento, compreensão, habilidades e motivação dos indivíduos a fim de adquirir valores e atitudes necessários para cuidar das questões ambientais e encontrar soluções sustentáveis (DIAS, 2004).

Nesse sentido, o desenvolvimento sustentável contempla a busca de uma efetividade econômica, social e ambiental cujas características incluem a valorização dos recursos naturais com geração de renda, respeito à diversidade cultural, participação popular nas decisões e gestão dos recursos, assim como a valorização do etnosaber (ARAÚJO; ARAÚJO, 2011).

Diante do exposto, o objetivo principal desse trabalho consiste em construir um plano de ações voltado ao saneamento que considere os princípios da sustentabilidade e contribua para a melhoria das condições locais de saúde da Comunidade Tradicional Remanescente Quilombola Vila Esperança do distrito de Mariental no município da Lapa, PR.

\section{MATERIAIS E MÉTODOS}

O estudo foi desenvolvido para atender ao déficit dos serviços de saneamento da Comunidade Tradicional Remanescente Quilombola Vila Esperança de Mariental localizada no município da Lapa, PR. A cidade localiza-se na região sul do estado, Mesorregião Metropolitana de Curitiba. Sua área total é de $2.093,859 \mathrm{~km}^{2}$ e a área urbana compreende aproximadamente $17,84 \mathrm{~km}^{2}$ (IBGE, 2014; PML, 2015).

A CRQ Vila Esperança está localizada no distrito de Mariental, região leste da Lapa, a aproximadamente $20 \mathrm{~km}$ do centro da cidade. Possui uma área territorial de aproximadamente 12,75 ha, situada a 950 metros acima do nível do mar, com acesso pela BR 476 (Rodovia do Xisto), e localiza-se nas coordenadas geográficas latitude $25^{\circ} 43^{\prime} 7.38^{\prime \prime}$ Sul e longitude 49³7'29.90" Oeste.

A comunidade é formada por afrodescendentes que viveram na região da Lapa na condição de escravos e receberam terras na localidade do Feixo, no distrito de Mariental. Fazia parte da Fazenda Santa Amélia, de Hipólito Alves de Araújo, que, inspirado pelo movimento abolicionista, liberou os negros que eram de sua propriedade antecipando a Lei Áurea de 13 de maio de 1888. Na condição de ex-escravizados, os negros foram presenteados por Araújo com as terras que eram cultivadas por eles (PAULA, 2007). Posteriormente, parte da comunidade permutou seus terrenos originais em uma negociação realizada com um fazendeiro lindeiro e formou-se a Vila Esperança. Ela teve seu certificado de autorreconhecimento expedido pela Fundação Cultural Palmares em 14/11/2006, com certidão registrada no livro de cadastro geral no 08, reg. 798, fl. 10, Diário Oficial da União 13/12/2006 (PARANÁ, 2010).

Para alcançar o objetivo proposto neste trabalho, primeiramente foram levantadas as condições atuais da comunidade, identificando as principais fragilidades. Posteriormente, foi elaborado um plano de ações que inclui práticas de habitação e saneamento com vistas à sustentabilidade e que, articulado com a educação ambiental, possam conduzir a comunidade a uma situação desejável, do ponto de vista ambiental e social.

Tal estudo foi realizado em duas fases, sendo a primeira para reconhecimento da realidade local e a segunda fase para levantamento de dados ambientais da região. Em setembro de 2015, foi realizada visita a CRQ Vila Esperança, quando foram levantados dados relacionados às condições socioeconômicas e de saúde ambiental por meio de observações, registros fotográficos e entrevistas semiestruturadas. Na ocasião foram visitadas 93\% das residências.

O roteiro de entrevistas foi elaborado por meio de adaptações dos temas geradores sugeridos no Caderno metodológico para ações de educação ambiental e 
mobilização social em saneamento do Ministério das Cidades (BRASIL, 2009), composto de questões abertas e fechadas. A primeira teve como objetivo identificar o número de moradores das residências, a faixa etária, o sexo, a escolaridade e a situação atual em relação ao trabalho ou estudo. A segunda foi elaborada de forma a avaliar as condições mínimas de infraestrutura das residências. A terceira buscou levantar as condições de saúde da população por meio da percepção dos próprios moradores. A quarta foi elaborada para identificar a infraestrutura de saneamento da comunidade. E, por fim, a última questão objetivou o levantamento das condições socioeconômicas das famílias. Após a coleta, os dados foram tabulados em planilhas no programa Excel, onde foram expressos em frequências e percentuais, por meio dos quais foram gerados gráficos que permitiram a visualização de forma mais clara e objetiva.
Na segunda fase foram determinados os índices endêmicos do município e as características ambientais da região de estudo, tendo como base fontes públicas e considerando as características de uso e ocupação do solo, clima, áreas de conservação e/ou preservação, hidrografia e geologia.

Tendo como base o levantamento prévio das condições socioeconômicas e ambientais da comunidade e a análise dos indicadores de saneamento, foi proposto um plano de ações. Para tanto foram levantadas, por meio da revisão da literatura, legislação e normas regulamentadoras pertinentes, soluções de baixo custo e de simples implantação que conduzam a resolução das questões apresentadas e que sejam compatíveis para implementação na área estudada, de forma a se tornar um instrumento prático de intervenção. Também foram elencados Programas do Governo Federal que possam financiar a implementação de tais soluções.

\section{RESULTADOS E DISCUSSÃO}

A CRQ Vila Esperança está localizada em uma área de terreno irregular, com as residências agrupadas por núcleos de laços familiares e distantes entre si, o que possibilitou a divisão teórica das áreas para facilitar a implantação de sistemas de saneamento e as ações de educação ambiental. O número de moradores e de residências destas áreas, levantados em setembro de 2015, é apresentado na Tabela 1.

Em relação aos serviços básicos de saneamento, as residências recebem abastecimento de água tratada por rede geral, com exceção das que não possuem infraestrutura sanitária. Entretanto, o principal problema verificado e apontado pelos moradores é a destinação dos esgotos domésticos, tendo em vista que todas as resi- dências despejam as águas cinzas, que são efluentes provenientes das pias de cozinha, tanque de roupas e chuveiro, diretamente no solo e cerca de 40 casas utilizam fossas rudimentares para disposição do efluente dos banheiros. Porém, todas as fossas estão cheias, algumas apresentam rachaduras, segundo relato dos moradores, e outras foram abertas para que possam drenar seu efluente superficialmente no solo. Com relação aos resíduos sólidos, verificou-se que cerca de $38 \%$ das famílias destinam todo o produzido por meio da queima, enquanto o restante das famílias destina uma parte para coleta e a outra é queimada. Os moradores não têm o hábito de separar o lixo para reciclagem. A coleta pública é feita uma vez por semana, segundo relatos dos moradores, porém o caminhão acessa apenas a

Tabela 1 - Número de residências e moradores da Comunidade Tradicional Remanescente Quilombola (CRQ) Vila Esperança.

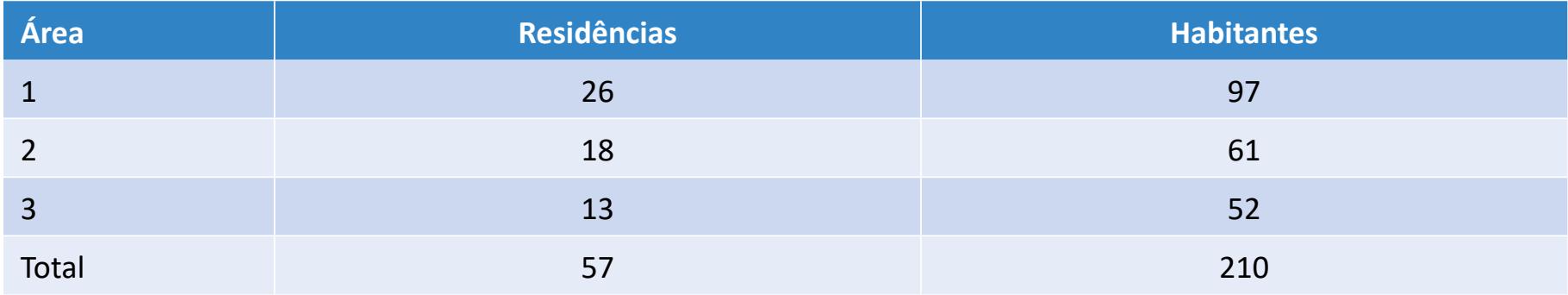

Fonte: o autor. 
área 1, devido à topografia e condições de infraestrutura inapropriadas nas demais áreas. Também não foram registradas a presença de lixeiras individuais e coletivas na região. Tais situações corroboram para a destinação dos resíduos de forma inadequada.

Diante da situação verificada de insalubridade ambiental, com esgoto sanitário despejado a céu aberto, em contato com pessoas, animais e hortaliças; resíduos sólidos sendo destinados por meio da queima ou espaIhados no solo; as péssimas condições das residências, sem infraestrutura mínima de saneamento e presença de frestas que permitem a passagem de vetores e intempéries e, ainda, a deficiência das condições socioeconômicas, identificou-se a necessidade de intervenções no âmbito do saneamento ambiental, de forma a promover condições mínimas de saúde e bem-estar, inclusão social e a proteção do meio ambiente. Para tanto, foram definidas as linhas de ação apresentadas na Figura 1, para as quais foram elaboradas condicionantes com vistas à sustentabilidade local e foco na resolução das questões observadas.
Para atender as necessidades de saneamento da habitação buscou-se, como base, o programa Melhorias Sanitárias Domiciliares da Fundação Nacional de Saúde (FUNASA), que tem como um de seus objetivos equipar os domicílios com melhorias sanitárias necessárias à proteção das famílias e à promoção de hábitos higiênicos, e, ainda, o Programa Brasil Quilombola, por meio do Eixo 2: Infraestrutura e Qualidade de Vida.

A partir da identificação das residências que necessitam de estruturação sanitária, foram propostas a adequação das instalações, para as quais foram elaborados projetos de engenharia que as contemple.

Para o atendimento da deficiência de estruturas de esgotamento sanitário para a comunidade foram considerados os sistemas de coleta, transporte e tratamento de esgoto. Como concepção inicial dos sistemas, foi realizado o levantamento topográfico, que teve como objetivo verificar o melhor aproveitamento das condições locais tendo em vista a necessidade de priorização da condução do esgoto sanitário por meios gravitacio-

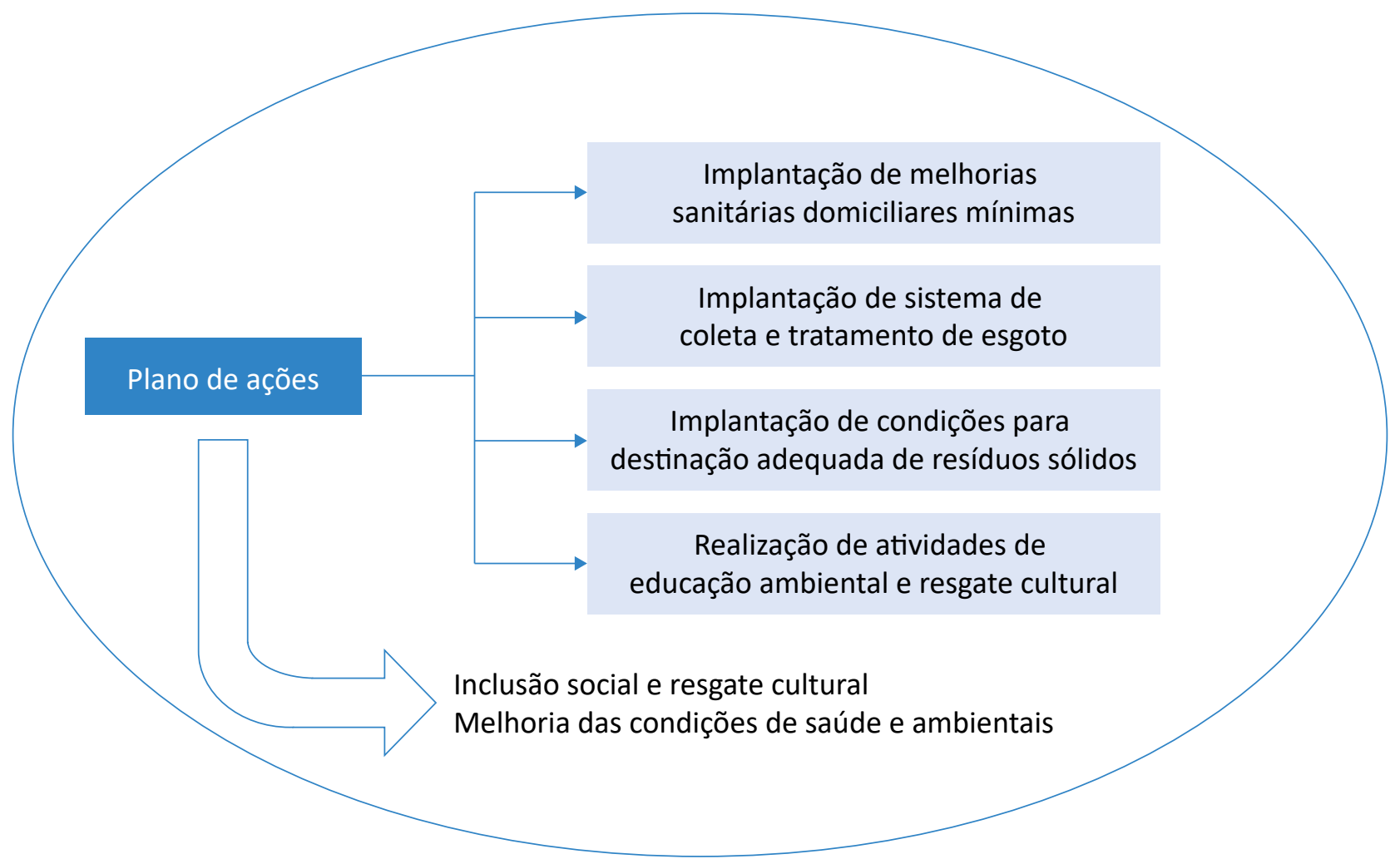

Figura 1 - Plano de ações para a Comunidade Tradicional Remanescente Quilombola (CRQ) Vila Esperança. 
nais. Dessa forma, teve o objetivo de reduzir os custos com energia para a condução até o tratamento, bem como conhecer o relevo da região, delimitar a área, definir o local de implantação das unidades de tratamento de esgoto e desenvolver a planta situacional da comunidade permitindo a indicação de soluções para as necessidades apontadas que sejam compatíveis com a topografia da região.

De acordo com o levantamento realizado, verificou-se que a área em estudo possui declividades acentuadas, requerendo a implantação de três sistemas distintos para coleta e tratamento do esgoto, permitindo que funcione por gravidade, evitando-se a implantação de estações elevatórias. As extensões totais de rede coletora por área de atendimento são apresentadas na Tabela 2. Na Figura 2 é apresentada a divisão teórica das áreas.

Com base na taxa de crescimento do município da Lapa foi possível definir a população estimada para os próximos 30 anos nas áreas do projeto. Os parâmetros adotados no dimensionamento dos sistemas de tratamento estão apresentados na Tabela 3.

Para o tratamento do esgoto sanitário foram consideradas opções simples, eficientes e de fácil manutenção, o mais compatível possível com as condições naturais, climáticas e de disponibilidade de área, sendo considerados os sistemas de zona de raízes precedidos por fossa séptica e filtros anaeróbios de fluxo ascendente, conforme esquema apresentado na Figura 3. Para a destinação do efluente dos sistemas foi optado pela implantação de sumidouros.

Para a melhor distribuição e acomodação do esgoto afluente, foi proposta a implantação de duas unidades

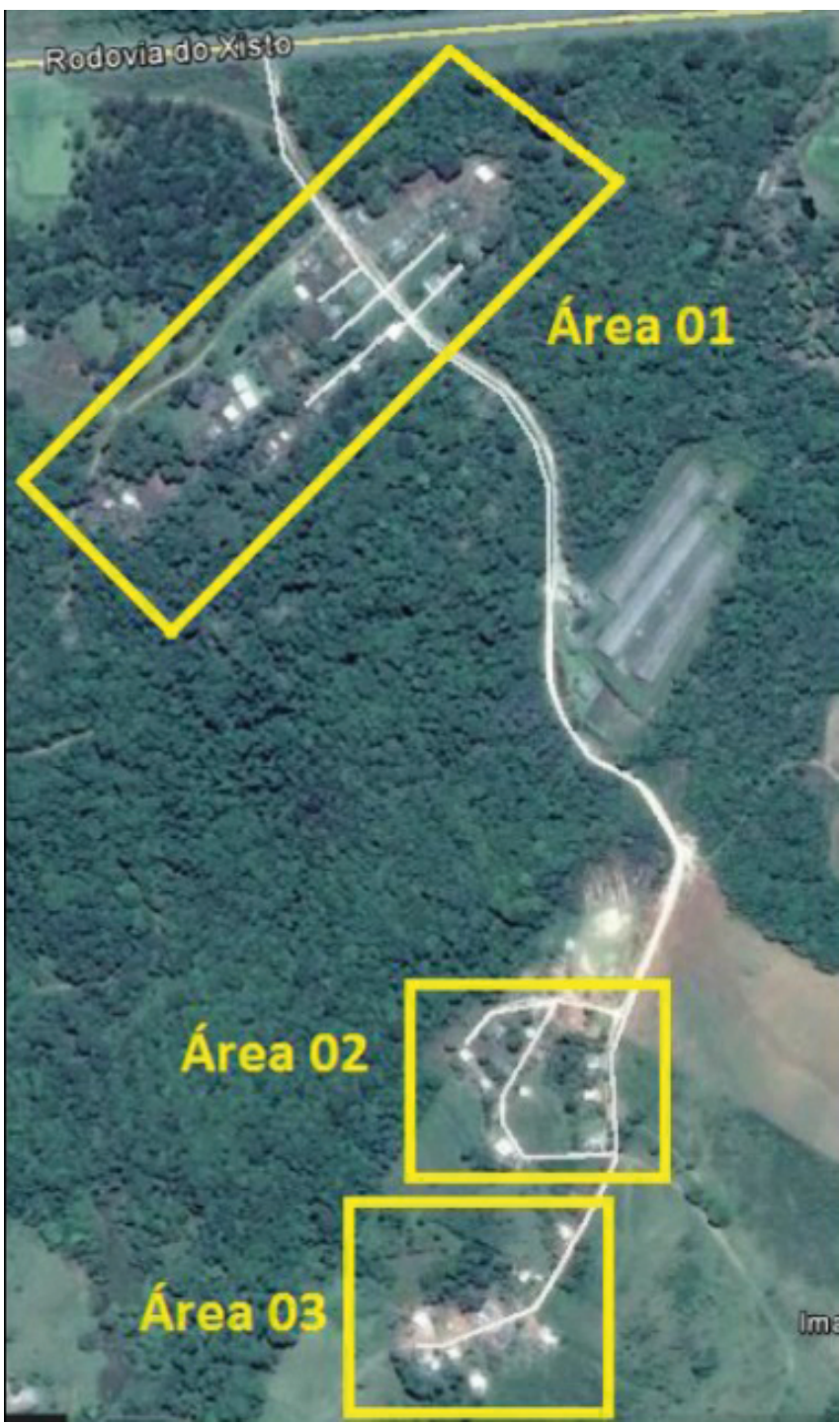

Fonte: adaptado de Google Maps.

Figura 2 - Divisão de áreas da Comunidade Tradicional Remanescente Quilombola (CRQ) Vila Esperança para efeitos de projeto de esgotamento sanitário.

Tabela 2 - Extensão das redes coletoras.

\begin{tabular}{l|r} 
Região & Extensão da re \\
\hline Área 1 & 665,92 \\
\hline Área 2 & 365,36 \\
\hline Área 3 & 282,31 \\
\hline Extensão total & $1.313,59$
\end{tabular}

Fonte: Arndt, Felisbino e Rocha (2014). 
de fossa séptica, sucedidas por duas unidades de filtro anaeróbio de fluxo ascendente em cada estação de tratamento. Quanto ao material filtrante, foi previsto o uso de pedra brita no 4 e a altura dos dispositivos limitada a 1,20 m (ABNT, 1997). A altura do fundo falso é de $0,40 \mathrm{~m}$ e do leito filtrante $0,50 \mathrm{~m}$.

O sistema de zona de raízes de fluxo horizontal foi a opção escolhida já que apresenta maior simplicidade no funcionamento e na manutenção quando comparado aos sistemas de fluxo vertical, que requerem a alimentação intermitente e têm necessidade de bombeamento. Outro fator relevante na escolha deve-se ao fato de que o sistema escolhido garante completo afastamento do esgoto em relação aos demais sistemas, que requerem a alimentação na superfície, evitando o contato de pessoas e animais. Além disso, o sistema de zona de raízes de fluxo horizontal atende a principal finalidade de garantir o tratamento do esgoto, de forma a meIhorar as condições de saúde da população e as condições ambientais. $O$ sistema proposto também atende a perspectiva da sustentabilidade no saneamento, apresentando-se como uma alternativa eficiente, equitativa e autossuficiente, não necessitando de energia elétrica para o seu funcionamento, emprega materiais locais para a sua construção, apresenta simples operação e manutenção e melhoria significativa na qualidade final do efluente, podendo representar fonte de renda para as famílias atendidas com a produção de flores ornamentais de interesse comercial.

Os sistemas de zonas de raízes foram dimensionados para atender a uma demanda atual e futura que garanta uma DBO efluente mínima de $30 \mathrm{mg} / \mathrm{L}$. Como material de recheio foi adotado o uso de pedra brita no 3 , e areia grossa, como material filtrante. Para a imper-

Tabela 3 - Parâmetros de dimensionamento do sistema de tratamento de esgoto.

\begin{tabular}{|l|c|c|c|}
\hline Parâmetros & Área 1 & Área 2 & Área 3 \\
\hline População atendida (hab.) & 130 & 82 & 70 \\
\hline Vazão média de esgoto (L/s) & 0,20 & 0,12 & 0,10 \\
\hline Vazão média de esgoto (m³/dia) & 17,28 & 10,37 & 8,64 \\
\hline Vazão máxima de esgoto (L/s) & 0,36 & 0,22 & 0,18 \\
\hline Carga DBO doméstica (kg/dia) & 7,02 & 4,43 & 3,78 \\
\hline Concentração total DBO (mg/L) & 406,25 & 427,28 & 437,50 \\
\hline
\end{tabular}

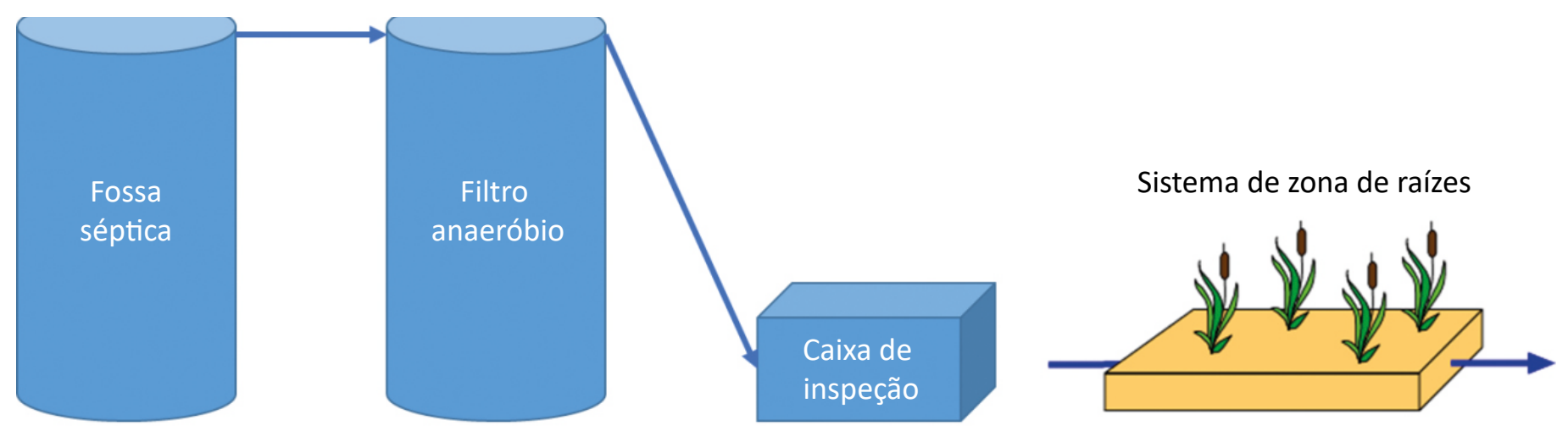

Figura 3 - Esquema da disposição dos sistemas de tratamento de esgoto. 
meabilização do sistema foi previsto o uso de manta de polietileno com espessura mínima de 0,8 micra (RODRIGUES, 2012).

Para o dimensionamento dos sistemas de zona de raízes de escoamento subsuperficial de fluxo horizontal foi utilizado o modelo oriundo da cinética de primeira ordem, com parâmetro $\mathrm{DBO}_{5}$ aplicado a reatores tipo pistão. Os valores de entrada de matéria orgânica foram 97,5 mgDBO/L, 102,55 mgDBO/L e 8,64 mgDBO/L, para os sistemas 1,2 e 3 , respectivamente, considerando uma eficiência de remoção de matéria orgânica de $40 \%$ na fossa séptica e $60 \%$ no filtro anaeróbio (FLORENCIO et al, 2010). As vazões assumidas foram $17,28 \mathrm{~m}^{3} /$ dia para o sistema $1 ; 10,37 \mathrm{~m}^{3} /$ dia para o sistema 2 e $8,64 \mathrm{~m}^{3} /$ dia para o sistema 3 .

Foram assumidos: $\mathrm{K}_{20}=0,70 \mathrm{~d}^{-1}$ e temperatura crítica de $10^{\circ} \mathrm{C}$, resultando em um valor de $\mathrm{K}_{\mathrm{t}}=0,39 \mathrm{~d}^{-1}$, aproximadamente. Foi adotado $\mathrm{n}=0,35$ (PHILIPPI; SEZERINO, 2004), tendo em vista a predominância de solos porosos na região, uma profundidade média de 0,60 m para cada sistema e uma DBO efluente de $30 \mathrm{mg} / \mathrm{L}$ (RODRIGUES, 2012). A relação comprimento:largura mínima respeitada para cada sistema foi de 2:1 (PHILIPPI; SEZERINO, 2004).

A escolha da macrófita empregada no projeto foi feita por meio da revisão de literatura e discussão com os representantes da PML, que optaram pelo emprego de plantas ornamentais comuns na região e por representarem a possibilidade de geração de renda as famílias. Sendo assim, foi previsto o emprego de plantas da espécie Zantedeschia aethiopica conhecida popularmente como copo-de-leite (ZURITA; ANDA; BELMONT, 2009).

Para o atendimento da demanda de resíduos sólidos foram propostas a implantação de lixeiras que permitam o acondicionamento dos resíduos até a coleta, a implantação de uma unidade de separação de recicláveis, tendo em vista que o processo já ocorre de maneira informal pelos moradores e, ainda, a implantação de duas unidades de vermicomposteiras, prática já adotada no município. Para o dimensionamento das unidades foram adotados os valores de geração per capita do município, obtidos por meio do Plano Municipal de Saneamento Básico da Lapa de 2014, de 0,612 kg/hab.dia.

Para a destinação do composto gerado nas vermicomposteiras foram previstas a construção de duas hortas comunitárias posicionadas de forma que possam, futuramente, receber os efluentes tratados do esgoto sanitário, uma vez que o cultivo é pratica comum na comunidade.

Para atender às demandas identificadas, encontrou-se como possível forma de subsídio financeiro o Programa Brasil Quilombola, por meio do Eixo 2: Infraestrutura e Qualidade de Vida.

Todavia, para que os projetos propostos alcancem seus objetivos, fica evidente a necessidade de um projeto de Educação Ambiental (EA) que estimule a participação social na transformação da realidade e os torne sujeitos ativos na aplicação das soluções. O projeto proposto foi elaborado de forma independente das ações a serem implementadas, tendo em vista que a liberação de recursos pelo órgão competente não é vinculada à implementação de sistemas e sim à EA.

Desta forma, para o desenvolvimento das ações de EA na CRQ Vila Esperança, foi desenvolvido um projeto básico seguindo as recomendações constantes no edital de chamamento público no 02/2015/DESAM/FUNASA/MS.

Na composição da base teórico-metodológica que estrutura a proposta de intervenção socioambiental, foi utilizada a metodologia da problematização e sua sistematização por meio do Método do Arco, proposto por Charles Marguerez, descrito por Bordenave (1977) e adaptado por Michalizen (1999). Tal metodologia indica o reconhecimento da capacidade do indivíduo que, na qualidade de sujeito ativo do processo de pesquisa, percebe-se estimulado a intervir sobre sua própria realidade como agente de transformação a partir de problemas reais percebidos por meio da observação direta da realidade.

O projeto de EA proposto, intitulado Semeando o Futuro na Vila Esperança, tem como linhas de ação o fortalecimento da identidade local, a elaboração de diagnóstico participativo, a identificação e apresentação de ações para resolver as questões levantadas pelos moradores e a implantação dessas ações com participação popular.

Para cada linha de ação foram determinadas as etapas e desenhadas as estratégias de participação. As linhas de ação e os objetivos propostos em cada linha são apresentados na Figura 4.

A proposta de resgate da memória cultural baseia-se na tentativa de construção do presente por meio do 


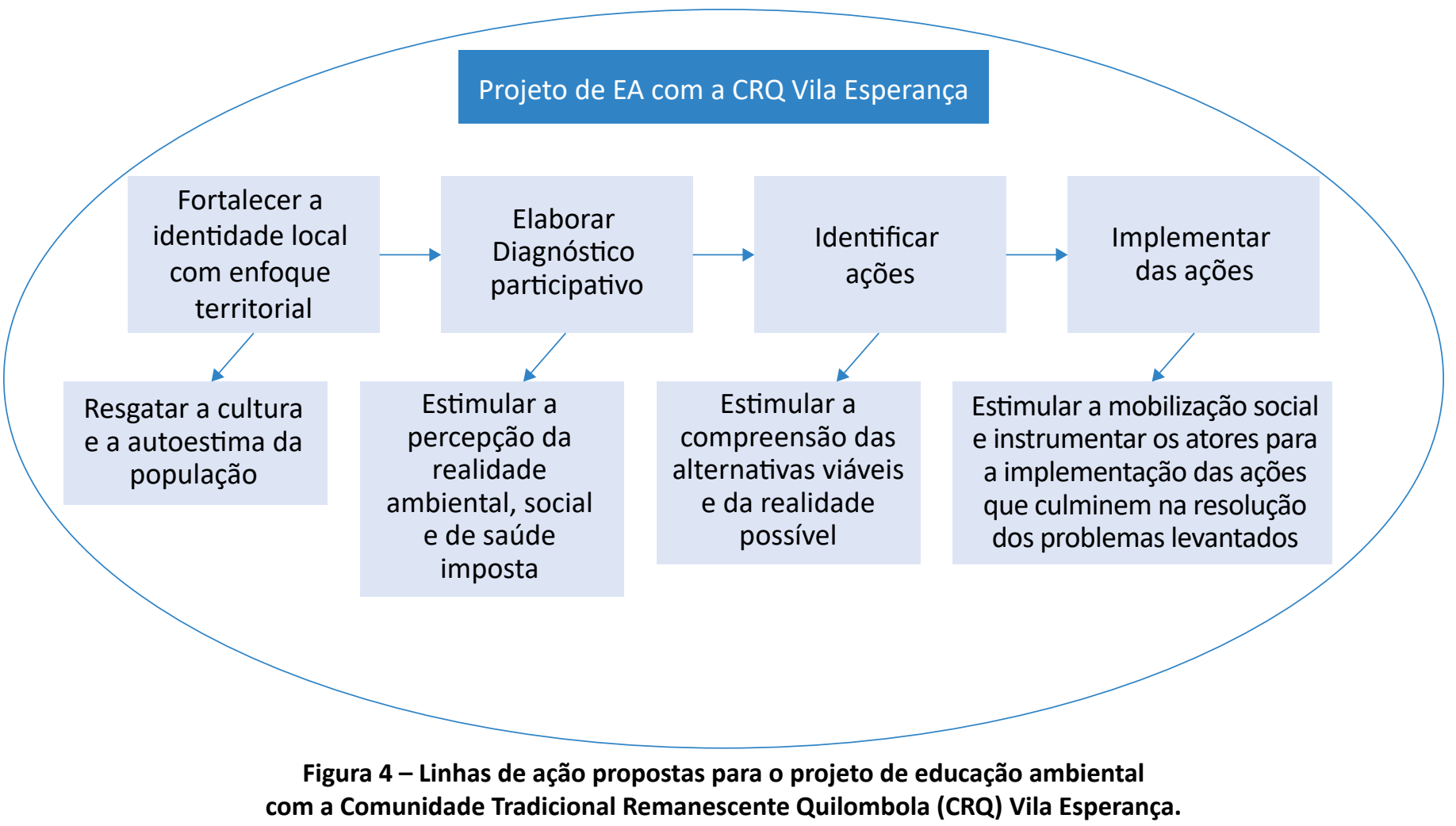

conhecimento adquirido no passado. Nesse sentido, Bomfim (2012) destaca que a memória e a oralidade são ferramentas de socialização necessárias à construção de um projeto coeso e futuro dos elementos culturais nos territórios quilombolas. Da mesma forma, a capacidade de adaptação e organização cultural permite aos indivíduos a singularidade de dominar, a partir de estruturas simbólicas, os atributos culturais necessários ao desenvolvimento de práticas e ações que se evidenciam na intervenção da realidade, de acordo com as habilidades e controle dos mecanismos de sociabilidade gerados pelos valores simbólicos constitutivos do padrão social específico local.

A elaboração de diagnóstico participativo busca instrumentalizar os atores para a percepção da realidade. Nesse âmbito, Ruscheinsky e Costa (2012) afirmam que o posicionamento teórico em face da EA permite a compreensão das alternativas viáveis e a reflexão a respeito da realidade imposta e da realidade possível.

O enfoque territorial como base para os processos de planejamento do desenvolvimento permite adequar as transferências de recursos às reais necessidades das regiões, que podem ser melhor captadas por meio de processos participativos de diagnóstico e elaboração de projetos, proporcionado que determinadas características locais sejam valorizadas à exemplo dos atributos naturais e da herança cultural de uma localidade (BEDUSCHI FILHO; ABRAMOVAY, 2004).

Dessa forma, o projeto de EA proposto busca aliar a experiência popular ao saber técnico e científico, conduzindo as práticas populares para a transformação da realidade apresentada.

\section{CONSIDERAÇÕES FINAIS}

Historicamente, com a forte incidência de doenças, percebeu-se a importância das intervenções de saneamento na prevenção da saúde (PHILIPPI JR.; SILVEIRA,
2004). A partir de então, com a ampliação das discussões, as intervenções de saneamento saíram de uma abordagem sanitária clássica, e passaram a uma abor- 
dagem ambiental, que visa assegurar um meio ambiente adequado à saúde humana e de outros seres vivos (SOARES; BERNARDES; CORDEIRO NETTO, 2002).

Dessa forma, promover a saúde por meio da implantação de sistemas adequados de saneamento significa minimizar ou eliminar as diversas doenças que têm no meio ambiente uma fase de seu ciclo de transmissão. Entretanto, além da implantação de sistemas de saneamento, o controle da transmissão de doenças completa-se quando é promovida a educação sanitária, adotando-se hábitos higiênicos como utilização e manutenção adequadas das instalações sanitárias, meIhoria da higiene pessoal e segurança alimentar.

Sendo assim, as ações de saneamento devem ir além da implantação de sistemas de engenharia, possuindo uma base sólida, fundamentada na educação ambiental e na participação popular, respeitando os aspectos culturais, sociais, ambientais e as limitações econômicas (PHILIPPI JR.; MALHEIROS, 2005).

Todavia, apesar do amplo conhecimento sobre a importância do saneamento na prevenção e na promoção da saúde, o panorama brasileiro aponta para uma realidade desfavorável, com índices e taxas de cobertura ainda insuficientes, configurando-se como um grave problema social e de saúde pública. Tal situação se agrava quando são analisadas as situações de comunidades situadas em áreas rurais ou periurbanas, caso das comunidades tradicionais que sofrem com a ineficácia ou ausência total de ações em saneamento.

A Comunidade Tradicional Remanescente Quilombola Vila Esperança é um claro exemplo, onde verifica-se a situação de desigualdade social apontada por Barros (2007), materializada pela ausência de direitos essenciais, resultando em baixa escolaridade, desemprego, condições precárias de habitação e falta de acesso a serviços de saneamento e saúde.

Nesse cenário, a implantação de sistemas descentralizados de engenharia para suprir a demanda de saneamento deve visar a prevenção e a promoção da saúde, por meio da melhoria das condições ambientais.

A proposta de mudança baseou-se na implantação de sistemas que supram as carências de saneamento ambiental da comunidade, vislumbrando a sustentabilidade local. Para tanto, foram previstas a implantação de sistemas de tratamento de esgoto, o manejo adequado de resíduos sólidos e a implantação de hortas comunitárias.

A primeira etapa do estudo, que consistiu na elaboração do levantamento preliminar da comunidade, foi fundamental, tendo em vista que possibilitou definir as principais demandas da população, as condições sanitárias e as características ambientais da região, além de levantar dados pertinentes à elaboração dos projetos de engenharia e a necessidade do envolvimento da população na busca pela melhoria da qualidade de vida e preservação ambiental.

Tal levantamento apontou o caminho para a busca das soluções propostas, que permeou a implantação de sistemas que permitam a participação popular de forma efetiva, que apresente simples manutenção e operação, e que sejam sustentáveis, buscando a apropriação de materiais de fácil aquisição local, que não gaste energia para a operação, que possa contribuir na geração de renda e promova a melhoria das condições ambientais locais e de saúde da população.

A solução encontrada para o atendimento do déficit de esgotamento sanitário baseou-se na implantação de três sistemas simples compostos por fossas sépticas, seguidas por filtros anaeróbios de fluxo ascendente e, como polimento final do efluente, a adoção de sistemas de zona de raízes. A adoção de três sistemas independentes para o tratamento de esgoto baseou-se no levantamento e projeto de redes já realizadas por Arndt, Felisbino e Rocha (2014), que se aproveitou da topografia da região para condução do esgoto por meios gravitacionais, não necessitando de energia elétrica. Os sistemas de zonas de raízes foi escolhido pela adoção de fluxo horizontal subsuperficial, pois, além de apresentar-se como opção eficiente na remoção de matéria orgânica e micro-organismos, representando alternativa de reúso do efluente na agricultura, o regime de fluxo proporciona o completo afastamento do esgoto, garantindo a segurança sanitária da população e animais. Quanto à vegetação, optou-se pelo cultivo da planta ornamental Zantedeschia aethiopica (copo-de-leite) tendo em vista que, além de ser uma espécie comum na região, pode se tornar uma alternativa de geração de renda para a comunidade com a comercialização das mesmas.

Contudo, é evidente que a implantação de tais sistemas não atingirá seus objetivos se a população não tiver infraestrutura sanitária domiciliar mínima, como 
na situação encontrada, onde várias residências não dispõem de banheiros e algumas delas não têm pia na cozinha. Para tanto, foi proposta a implantação de banheiros e pias nas cozinhas nas residências deficitárias, com a elaboração de projetos de engenharia que possam atender tal carência.

Todavia, nenhum projeto de engenharia será efetivo se não houver um entendimento da importância das ações e um engajamento da população na condução das transformações. Por essa razão, sugere-se como alternativa buscar a participação popular no saneamento, por meio do envolvimento da população nas tomadas de decisão e na efetiva implantação dos sistemas e melhorias. Esta alternativa pode representar maior sustentabilidade aos serviços de saneamento e mitigar problemas socioeconômicos.

Nessa perspectiva, foi proposto um projeto de educação ambiental que proporcione a percepção da realidade e estimule a compreensão de como algumas ações individuais podem comprometer o meio ambiente e repercutir no coletivo. Além disso, o projeto tem como uma de suas linhas de ação o fortalecimento da identidade local com o propósito de resgatar a cultura e a autoestima da população e estabelecer um diálogo entre o saber tradicional e o conhecimento científico.

Partindo de bases conceituais, busca agregar conhecimentos sobre novas e positivas formas de abordagem e planejamento de soluções socioambientais e de saneamento básico, favorecendo o processo de desenvolvimento local com sustentabilidade. Demonstrando-se, assim, a necessidade do reconhecimento e da preven- ção dos agravos decorrentes de um meio ambiente desfavorável, bem como a importância de evitar as enfermidades relacionadas às exposições ambientais.

Espera-se que a concretização deste trabalho forneça ferramentas para que os agentes públicos possam buscar os recursos financeiros necessários à mudança da realidade observada e, ainda, que possam entender a importância da participação popular na condução das transformações, buscando conciliá-las com a capacitação e sensibilização dos agentes envolvidos.

Enfim, a implantação de sistemas de saneamento como promoção da saúde busca a salubridade ambiental da região e, consequentemente, a minimização de doenças relacionadas à poluição e contaminação ambiental. Além disso, a valorização do conhecimento e a participação popular visam a formulação conceitual da promoção da saúde por meio do funcionamento pleno, duradouro e acessível dos serviços a toda a população.

A utilização de produtos locais de baixo custo e fácil aquisição visam a sustentabilidade econômica das ações propostas, já a valorização do saber tradicional visa a sustentabilidade cultural da população. A sustentabilidade ecológica será promovida por meio da conservação do meio ambiente e a ambiental por meio das ações de educação ambiental. Busca-se, ainda, o alcance da dimensão social com a melhoria da qualidade de vida da população e aumento da geração de renda, a dimensão territorial por intermédio de estratégias de desenvolvimento ambientalmente seguras e, por fim, a dimensão política por meio do envolvimento do município para a implantação das ações.

\section{REFERÊNCIAS}

ARAÚJO, J. J. C. N.; ARAÚJO, J. D. N. As comunidades tradicionais e o programa zona franca verde: Cenários no sudoeste do Amazonas - Brasil. Millenium, n. 41, p. 47-67, 2011.

ARNDT, L. V.; FELISBINO, R. M.; ROCHA, W. H. Sistema alternativo de coleta e tratamento de esgoto para comunidades rurais: Estudo de caso: Comunidade Remanescente Quilombola Vila Esperança-Município da Lapa/PR. Trabalho de Conclusão de Curso (Graduação em Engenharia Civil) - Universidade Positivo, Curitiba, 2014.

ARRUDA, R. "Populações Tradicionais" e a proteção dos recursos naturais em unidades de conservação. Ambiente \& Sociedade, n. 5, p. 79-92, 1999. http://dx.doi.org/10.1590/S1414-753X1999000200007

ASSOCIAÇÃO BRASILEIRA DE NORMAS TÉCNICAS (ABNT). NBR 13969: Tanques Sépticos - Unidades de tratamento complementar e disposição final de efluentes líquidos - projeto, construção e operação. Rio de Janeiro: ABNT, 1997. 
ÁVILA, C.; BAYONA, J. M.; MARTÍN, I.; SALAS, J. J.; GARCIA, J. Emerging organic contaminant removal in a full-scale hybrid constructed wetland system for wastewater treatment and reuse. Ecological Engineering, v. 80, p. 108-116, 2015. http://dx.doi.org/10.1016/j.ecoleng.2014.07.056

BARBOSA, G. S. O desafio do desenvolvimento sustentável. Revista Visões, v. 1, n. 4, 2008.

FLORENCIO, L. BASTOS, R. K. X.; AISSE, M. M. Tratamento e utilização de esgotos sanitários. PROSAB. Rio de Janeiro: ABES, 2006.

BARROS, E. P. Quilombo, resistência e movimentos negros. 2007. Disponível em: <http://static.recantodasletras.com. br/arquivos/1300029.pdf>. Acesso em: out. 2016.

BEDUSCHI FILHO, L. C.; ABRAMOVAY, R. Desafios para o desenvolvimento sustentável das regiões rurais. Nova Economia, n. 14, p. 35-70, 2004.

BEZERRA, M. C. L.; BURSZTYN, M. (Orgs.). Ciência e Tecnologia para o Desenvolvimento Sustentável. Brasília: Ministério do Meio Ambiente; Instituto Brasileiro do Meio Ambiente e dos Recursos Naturais Renováveis: Consórcio CDS/UnB/ Abipti, 2000.

BOMFIM, G. G. Entre o cotidiano e a memória: a construção da identidade no contexto do patrimônio cultural no território quilombola. In: ENCONTRO BAIANO DE ESTUDOS EM CULTURA, 3., Bahia, 2012. Anais... Bahia: Universidade Federal do Recôncavo da Bahia, 2012.

BRASIL. Constituição da República Federativa do Brasil de 1988. Brasil, 1988. Disponível em: <http://www.planalto.gov. br/ccivil_03/constituicao/constituicao.htm>. Acesso em: dez. 2016.

. Ministério das Cidades. Caderno de Saneamento Ambiental. Brasília: Ministério das Cidades, 2004.

. Ministério das Cidades. Secretaria Nacional de Saneamento Ambiental. Programa de Educação Social Ambiental e Mobilização Social em Saneamento. Caderno metodológico para ações de educação ambiental e mobilização social em saneamento. Brasília: Ministério das Cidades, 2009.

. Secretaria Especial de Políticas de Promoção da Igualdade Racial. Secretaria de Políticas para Comunidades Tradicionais. Povos e comunidades tradicionais de matriz africana. Brasília: Secretaria Especial de Políticas de Promoção da Igualdade Racial, 2016.

. Secretaria Nacional de Políticas de Promoção da Igualdade Racial. Guia de implementação do Estatuto da Igualdade Racial. Brasília: Secretaria Nacional de Políticas de Promoção da Igualdade Racial, 2013.

CREDER, H. Instalações Hidráulicas e Sanitárias. Rio de Janeiro: LTC, 2015.

DIAS, G. F. Educação Ambiental: princípios e práticas. 9. ed. São Paulo: Gaia, 2004.

FUNDO DAS NAÇÕES UNIDAS PARA A INFÂNCIA (UNICEF). UNI: Relatório anual 2013. UNICEF, 2014. p. 3. Disponível em: <http://www.unicef.org/brazil/pt/UNI2013.pdf>. Acesso: jun. 2015.

HIJOSA-VALSERO, M.; REYES-CONTRERAS, C.; DOMÍNGUEZ, C.; BÉCARES, E.; BAYONA, J. M. Behaviour of pharmaceuticals and personal care products in constructed wetland compartments: Influent, effluent, pore water, substrate and plant roots. Chemosphere, v. 145, p. 508-517, 2016. https://doi.org/10.1016/j.chemosphere.2015.11.090

HOFFMANN, H.; PLATZER, C. A.; WINKER, M.; VON MUENCH; E. Technology review of constructed wetlands: subsurface flow constructed wetlands for greywater and domestic wastewater treatment. Alemanha: ECOSAN, 2011.

INSTITUTO BRASILEIRO DE GEOGRAFIA E ESTATÍSTICA (IBGE). Pesquisa Nacional por Amostra de Domicílios: Síntese de Indicadores. 2014. Disponível em: <http://biblioteca.ibge.gov.br/visualizacao/livros/liv94935.pdf>. Acesso: dez. 2016. 
INTERNATIONAL WATER ASSOCIATION (IWA). Specialist Group on Use of Macrophytes in Water Pollution Control. Constructed wetlands for pollution control: processes, performance, design and operation. Londres: IWA, 2000.

KAICK, T. S. V. Estação de tratamento de esgoto por meio de zona de raízes: uma proposta de tecnologia apropriada para saneamento básico no litoral do Paraná. 128f. Dissertação (Mestrado em Tecnologia) - Programa de Pós-Graduação em Tecnologia, Centro Federal de Educação Tecnológica do Paraná, Curitiba, 2002.

LEROY, J.; ACSELRAD, H.; Novas Premissas para a Construção de um Brasil Sustentável. In: RATTNER, H. Brasil no Limiar do Século XXI: Alternativas para a Construção de uma Sociedade Sustentável. São Paulo: Editora da Universidade de São Paulo, 2000. p. 183-210.

MENDONÇA, S. R.; MENDONÇA, L. C. Sistemas sustentáveis de esgotos. São Paulo: Blucher, 2016.

MICHALIZEN, M. S. O calidoscópio e a rede: estratégias e práticas de prevenção à AIDS e ao uso indevido de drogas. 229f. Tese (Doutorado em Ciências Sociais) - Pontifícia Universidade Católica de São Paulo, São Paulo, 1999.

NERY, T. C. S. Saneamento: ação de inclusão social. Estudos Avançados, v. 18, n. 50, p. 313-321, 2004. http://dx.doi. org/10.1590/S0103-40142004000100028

NOGUEIRA, R.; FERREIRA, I.; JANKNECHT, P.; RODRÍGUEZ, J. J.; OLIVEIRA, P.; BRITO, A. G. Energy saving wastewater treatment systems formulation of cost functions. In: INTERNATIONAL CONFERENCE ON WETLAND SYSTEMS FOR WATER POLLUTION CONTROL, 10., 2006, Lisboa. Proceedings Book. Almada: PAC - Artes Gráficas, 2006. p. 47-57.

PARANÁ. INSTITUTO DE TERRAS, CARTOGRAFIA E GEOCIÊNCIAS. Relatório do Grupo de Trabalho Clóvis Moura: 2005 2010. Curitiba: GTCM, 2010.

PAULA, F. M. C. Comunidades do Feixo e da Restinga: Herança dos Afro-descendentes da Lapa. Curitiba: Edição do autor, 2007.

PHILIPPI, L. S.; SEZERINO, P. H. Aplicação de sistemas tipo wetlands no tratamento de águas residuárias: Utilização de filtros plantados com macrófitas. Florianópolis: Ed. do autor, 2004.

PHILIPPI JR., A. Saneamento, saúde e ambiente: fundamentos para um desenvolvimento sustentável. Barueri: Manole, 2005.

PHILIPPI JR., A.; MALHEIROS, V. F. Saneamento e saúde pública: Integrando homem e meio ambiente. In: PHILIPPI JR., A. Saneamento, saúde e ambiente: fundamentos para um desenvolvimento sustentável. Barueri: Manole, 2005. p. 3-55.

PHILIPPI JR., A.; SILVEIRA, V. F. Saneamento ambiental e ecologia aplicada. In: PHILIPPI JR., A.; RÓMERO, M. A.; BRUNA, G. C. (Orgs.). Curso de gestão ambiental. Barueri: Manole, 2004. p. 19-52.

PREFEITURA MUNICIPAL DA LAPA. Sistema de Esgotamento Sanitário de Mariental e Feixo. Projeto de Engenharia. V. 1,2015

PRATA, R. C. C.; MATOS, A. T. M.; CECON, P. R.; LO MONACO, P. A. V.; PIMENTA, L. A. Tratamento de esgoto sanitário em sistemas alagados construídos cultivados com lírio-amarelo. Engenharia Agrícola, v. 33, n. 6, p. 1144-1155, 2013. http://dx.doi.org/10.1590/S0100-69162013000600007

PROGRAMA DAS NAÇÕES UNIDAS PARA OS ASSENTAMENTOS HUMANOS (UN-HABITAT). Constructed wetlands: manual. Water for Asian Citites Programme. Nepal, Kathmandu: UM-HABIT, 2008.

RODRIGUES, E. B. Tratamento de esgoto por zona de raízes: Experiências vivenciadas numa escola rural no município de Campos Novos/SC. 125f. Dissertação (Mestrado em Engenharia Ambiental) - Universidade Federal de Santa Catarina, Florianópolis, 2012. 
RUSCHEINSKY, A.; COSTA, A. L. A educação ambiental a partir de Paulo Freire In: RUSCHEINSKY, A. Educação Ambiental: abordagens múltiplas. 2. ed. Porto Alegre: Penso, 2012. p. 93-114.

SABEI, T. R. A inserção da educação ambiental não formal no processo de implantação de saneamento ambiental na comunidade rural Colônia Mergulhão. 99f. Dissertação (Mestrado em Ciências Ambientais) - Programa de Pós-Graduação em Ciência e Tecnologia Ambiental, Universidade Tecnológica Federal do Paraná, Curitiba, 2015.

SAHR, C. L. L.; LEGELSKI, F.; TOMASI, T. ALVES, A. P. F.; TUZINO, Y. M. M.; FERREIRA, P. Geograficidades quilombolas: estudo etnográfico da comunidade de São João, Adrianópolis - Paraná. Ponta Grossa: Editora: UEPG, 2011.

SANTOS, S. R. dos. Comunidades quilombolas: as lutas por reconhecimento de direitos na esfera pública brasileira. Porto Alegre: EDIPUCRS, 2014.

SCRIPTORE, J. S. Impactos do saneamento sobre sobre saúde e educação: uma análise espacial. 2016.206 p. Tese (Doutor em Ciências). Universidade de São Paulo, São Paulo, 2016.

SEZERINO, P. H.; BENTO, A. P.; DECEZARO, S. T.; MAGRI, M. E.; PHILLIPPI, L. S. Experiências brasileiras com wetlands construídos aplicados ao tratamento de águas residuárias: parâmetros de projeto para sistemas horizontais. Engenharia Sanitária e Ambiental, v. 20, n. 1, p. 151-158, 2015. http://dx.doi.org/10.1590/S1413-41522015020000096615

SILVA, A. A. Indicadores para avaliação de efeitos de intervenções de saneamento básico: a questão da sustentabilidade. 138f. Dissertação (Mestrado em Ciências) - Universidade de São Paulo, São Paulo, 2015.

SILVESTRE, D. O.; MOREIRA, A. P. C. Uso, vivência e conservação do meio ambiente em populações tradicionais: o caso da comunidade quilombola de caiana dos crioulos, Alagoa Grande-PB. Cadernos do Logepa, v. 6, n. 2, p. 180-202, 2012.

SOARES, S. R.; BERNARDES, R. S.; CORDEIRO NETTO, O. M. Relações entre saneamento, saúde pública e meio ambiente: elementos para a formulação de um modelo de planejamento em saneamento. Caderno de Saúde Pública, v. 18, n. 6, p. 1713-1724, 2002. http://dx.doi.org/10.1590/S0102-311X2002000600026

TILLEY, E.; ULRICH, L.; LÜTHI, C.; REYMOND, P.; ZURBRÜGG. Compendium of Sanitation Systems and Technologies. 2. ed. Suíça: SDC, 2014.

TREIN, C. M.; PELISSARI, C.; HOFFMANN, H.; PLTAZER, C. J.; SEZERINO, P. H. Tratamento descentralizado de esgotos de empreendimentos comercial e residencial empregando a ecotecnologia dos wetlands contruídos. Ambiente Construído, v. 15, n. 4, p. 351-367, 2015. http://dx.doi.org/10.1590/s1678-86212015000400055

UNITED STATES ENVIRONMENTAL PROTECTION AGENCY (USEPA). Constructed wetlands treatment of municipal wastewaters. Ohio: USEPA, 2000.

VALENTIM, R. P. F. de; TRINDADE, Z. A. Modernidade e comunidades tradicionais: memória, identidade e transmissão em território quilombola. Psicologia Política, v. 11, n. 22, p. 295-308, 2011.

VON SPERLING, M. Introdução à Qualidade das Águas e Tratamento de Esgotos. 2. ed. Belo Horizonte: Editora da Universidade Federal de Minas Gerais, 2014.

ZURITA, F.; ANDA, J.; BELMONT, M. A. Treatment of domestic wastewater and production of commercial flowers in vertical and horizontal subsurface-flow constructed wetlands. Ecological Engineering, n. 35, p. 861-869, 2009. http://dx.doi.org/10.1016/j.ecoleng.2008.12.026 